\title{
Therapeutic Applications of Carbon Monoxide
}

\author{
Melissa Knauert, Sandeep Vangala, Maria Haslip, and Patty J. Lee \\ Section of Pulmonary, Critical Care and Sleep Medicine, Yale University School of Medicine, 300 Cedar Street, TAC-441 South, \\ P.O. Box 208057, New Haven, CT 06520-8057, USA \\ Correspondence should be addressed to Patty J. Lee; patty.lee@yale.edu
}

Received 19 August 2013; Revised 21 October 2013; Accepted 5 November 2013

Academic Editor: Stefan W. Ryter

Copyright (c) 2013 Melissa Knauert et al. This is an open access article distributed under the Creative Commons Attribution License, which permits unrestricted use, distribution, and reproduction in any medium, provided the original work is properly cited.

\begin{abstract}
Heme oxygenase-1 (HO-1) is a regulated enzyme induced in multiple stress states. Carbon monoxide (CO) is a product of $\mathrm{HO}$ catalysis of heme. In many circumstances, $\mathrm{CO}$ appears to functionally replace $\mathrm{HO}-1$, and $\mathrm{CO}$ is known to have endogenous antiinflammatory, antiapoptotic, and antiproliferative effects. $\mathrm{CO}$ is well studied in anoxia-reoxygenation and ischemia-reperfusion models and has advanced to phase II trials for treatment of several clinical entities. In alternative injury models, laboratories have used sepsis, acute lung injury, and systemic inflammatory challenges to assess the ability of CO to rescue cells, organs, and organisms. Hopefully, the research supporting the protective effects of CO in animal models will translate into therapeutic benefits for patients. Preclinical studies of $\mathrm{CO}$ are now moving towards more complex damage models that reflect polymicrobial sepsis or two-step injuries, such as sepsis complicated by acute respiratory distress syndrome. Furthermore, co-treatment and post-treatment with CO are being explored in which the insult occurs before there is an opportunity to intervene therapeutically. The aim of this review is to discuss the potential therapeutic implications of $\mathrm{CO}$ with a focus on lung injury and sepsis-related models.
\end{abstract}

\section{Introduction}

Inducible heme oxygenase, heme oxygenase-1 (HO-1), is a regulated enzyme that is induced in response to oxidative stress. HO-1 catalysis is the rate limiting step in the breakdown of heme, a powerful intracellular catalyst of free radical production, to equimolar amounts of carbon monoxide (CO), biliverdin, and iron. Biliverdin is immediately converted to bilirubin and iron is rapidly sequestered into ferritin. CO remains behind as a stable, diffusible molecule with potent cell signaling capabilities. Experimentally we know that diverse insults such as ischemia, hypoxia, hyperoxia, endotoxin exposure, polymicrobial infection, ventilator induced lung injury, hemorrhage, and transplant cause $\mathrm{HO}-$ 1 upregulation at the transcriptional and, in a few cases, translational level.

In parallel with the elevation in $\mathrm{HO}-1, \mathrm{CO}$ levels are increased in multiple disease states such as asthma [1], cystic fibrosis [2], and sepsis [3]. Multiple experimental models have demonstrated that the pleiotropic effects of HO-1 can be mimicked via the application of exogenous CO. Given its safety in low doses [4-6] and relative ease of administration [7] compared to therapeutic HO-1 gene strategies, CO has been proposed as a therapeutic entity. This technology has already advanced as far as phase II trials for postoperative patients and patients with idiopathic pulmonary fibrosis, pulmonary hypertension, and chronic obstructive pulmonary disease (COPD). Because there is accumulating data regarding the ability of $\mathrm{CO}$ to abrogate primary and secondary acute lung injury (ALI) and control systemic inflammatory damage attributed to sepsis, there may one day be uses in the critical care setting.

$\mathrm{CO}$, the diatomic oxide of carbon, is a colorless, ubiquitous gas at temperatures above $-190^{\circ} \mathrm{C}$. It has a specific gravity of 0.967 relative to air and a density of $1.25 \mathrm{~g} / \mathrm{L}$ at standard temperature and pressure [8]. CO readily forms metal carbonyls, which are susceptible to the attack of the $\mathrm{CO}$ oxygen atom by electrophiles. Chemical reduction of $\mathrm{CO}$, however, requires temperatures well above the normal physiological range $\left(>100^{\circ} \mathrm{C}\right)$; metal carbonyls are relatively stable until CO is displaced, for example, by molecular oxygen [9]. Most of the CO in the body ( $80 \%)$ is bound to hemoglobin as $\mathrm{COHb}[10]$. The remainder of the $\mathrm{CO}$ is distributed in the tissues. The cellular concentrations of $\mathrm{CO}$ depend upon the local partial pressures of both $\mathrm{CO}$ and oxygen because the two gases compete for the same iron or copper binding 
CO inhalation

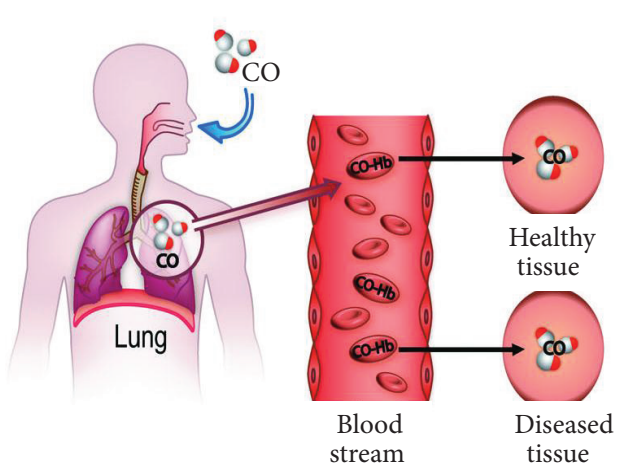

CO-RM administration (e.g., oral intake)

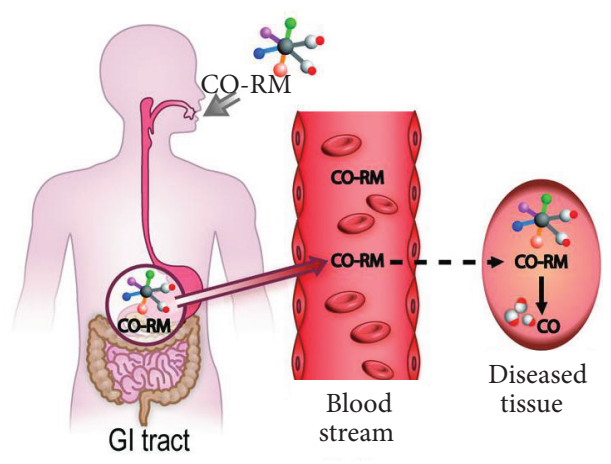

$\begin{array}{rcl}\text { Demanding } & \text { Dose control } & \text { No issue } \\ \text { None } & \text { Tissue specificity } & \text { Controllable } \\ \text { High } & \text { CO loads } & \text { Low } \\ \text { Yes } & \text { Specific equipment } & \text { None } \\ \text { Hospital } & \text { Administration setting } & \text { Ambulatory }\end{array}$

FIGURE 1: Alternative pathways for the therapeutic delivery of $\mathrm{CO}$ to diseased tissues with their main advantages and disadvantages. From Romao et al. (2012) [14].

sites. Among cellular heme proteins, myoglobin, cytochrome c oxidase, cytochrome p450, catalase, guanylate cyclase, and tryptophan dioxygenase bind sufficient $\mathrm{CO}$ to alter function in vitro. After binding to heme protein enzymes, $\mathrm{CO}$ usually inhibits electron transfer and/or catalytic activity [11].

Multiple actions of CO, of both exogenous and endogenous derivations, depend significantly on the concentrations of both $\mathrm{CO}$ and reduced transition metals, for example, $\mathrm{Fe}$ (II), in relation to the availability of molecular $\mathrm{O}_{2}$. In this respect, the $\mathrm{CO} / \mathrm{O}_{2}$ ratio and $\mathrm{O}_{2}$-dependent changes in the redox state of the cell, or in different compartments within a cell, assume critical importance in the effects of $\mathrm{CO}$ on specific protein functions. Because $\mathrm{CO}$ may influence the reactions involving heme proteins, it can be expected to have both pro-oxidant and antioxidant effects on the cell [12].

The only means of ridding the body of $\mathrm{CO}$ is through exhalation. $\mathrm{CO}$ is best known for its high affinity for hemoglobin and the resultant displacement of oxygen at high concentrations; this causes tissue hypoxia and the associated pathologies of $\mathrm{CO}$ poisoning. Maximal tolerated levels are generally considered to be $10-12 \%$ and are equivalent to the CO blood levels of heavy smokers. CO dosage is generally discussed in parts per million (ppm) and typical experimental doses of 250 to $500 \mathrm{ppm}$ result in $\mathrm{CO}$ serum levels well below $10 \%$ [4-6]. As the work to elucidate the physiologic and therapeutic role of gaseous $\mathrm{CO}$ has progressed, a parallel line of inquiry has produced a family of molecules known as $\mathrm{CO}$ releasing molecules (CO-RMs) capable of carrying and delivering $\mathrm{CO}$ to tissues in physiologic conditions [13]. The prototypic members of this family contain a transition metal core which binds (and then releases) CO. Technology has advanced these agents from lipid to water soluble and produced a large variety of compounds with varying potency and half-lives. See Figure 1, Romao et al. [14].

Sepsis is the leading cause of hospital mortality in adult patients and the incidence is increasing [15]. One recent study in the United States revealed 3.0 cases of severe sepsis (defined as sepsis plus organ dysfunction) per 1,000 people and 2.3 cases per 100 hospital discharges; mortality was $28.6 \%$ in this cohort $[16,17]$. When sepsis is combined with ALI or acute respiratory distress syndrome (ARDS) the outcomes are worse. ARDS associated with sepsis has a higher disease severity, poorer recovery, lower successful extubation rate, and higher mortality as compared to nonsepsis ARDS [18]. These vulnerable patients with sepsis and ARDS may potentially benefit from CO therapies, if safe doses as well as delivery systems can be established.

The goal of this review is to discuss potential therapeutic applications of $\mathrm{CO}$ in the clinical settings of sepsis and lung injury. Much of the focus will be upon the beneficial role of gaseous $\mathrm{CO}$, though we will briefly touch on related results from CO-RM therapies. The biologic and therapeutic potentials of biliverdin and bilirubin as well as HO-1 related therapy are beyond the scope of this review.

\section{Mechanisms of Action}

Carbon monoxide has been demonstrated to be dependent upon a variety of cell signaling pathways but neither a comprehensive list nor the precise molecular interactions have been fully worked out. It appears that CO exerts its effect through different pathways in different cell lines and under 
different conditions [19-22]. Most recently, investigators have revealed a role for HO-1 in the regulation of autophagy and mitochondrial homeostasis (reviewed in [23]). In addition, multiple members of the mitogen-activated protein kinase (MAPK) family are implicated in the anti-inflammatory and anti-apoptotic effects of $\mathrm{HO}-1$ and $\mathrm{CO}$; however, depending on the organ or tissue type, these effects can be dependent or independent of the three major MAPK pathways: p38, extracellular signal-regulated kinase (ERK) 1 and ERK2, and Jun Kinase (JNK). For example, an ERK1/2 MAPK dependent pathway has been shown to be responsible for CO-related inhibition of interleukin (IL) 17 in lung injury models; IL-17 plays a key role in neutrophil predominant inflammation of the lung [24]. In the case of a macrophage cell line and the p38 pathway, the effects of exogenous $\mathrm{CO}$ administration after lipopolysaccharide (LPS) insult require both mitochondrial produced reactive oxygen species (ROS) and the p38 MAPK pathway [25]. It may be that this mitochondrial burst of ROS is critical in the reported role of $\mathrm{CO}$ as a bactericidal agent. Our laboratory has shown that CO utilizes p38 $\alpha$ MAPK to attenuate oxidant-induced apoptosis in an ischemiareperfusion lung injury model via modulation of Fas/Fas ligand, B-cell lymphoma-2 (Bcl-2), and caspase-mediated cell death $[26,27]$. Activated phosphatidylinositol-3-kinase (PI3 K/Akt) also further induces HO-1 thereby creating a positive feedback loop [28-30]. The p38 dependent induction of HO-1 and/or CO are believed in some cases to target the p38 $\alpha$ isoform for degradation. This degradation functionally alters the $\mathrm{p} 38 \alpha$ to $\mathrm{p} 38 \beta$ ratios and promotes the dominance of the cytoprotective $\beta$ isoform [31]. More generalized activation of p38 MAPK by HO-1 also induces the expression of Bcell lymphoma-extra large protein via the PI3 K/Akt signal transduction pathway which, in turn, inhibits the intrinsic (mitochondrial) apoptotic pathway [31]. Both HO-1 and CO are protective in models of liver disease in which they prevent phosphorylation of the pro-apoptotic JNK MAPK [32].

In addition to MAPK related signaling, other antiapoptotic effects of $\mathrm{HO}-1$ are mediated through the nuclear factor $\kappa$-light chain-enhancer of activated B cells (NF- $\kappa \mathrm{B}$ ) transcription factor pathway. Via an unknown mechanism, HO-1 downmodulates NF- $\kappa$ B activation vis á vis apoptosis without interfering with the expression of downstream cytoprotective genes [21,31,33]. In the case of hypoxia, CO on its own can trigger activation of hypoxia inducible factor$\alpha$ which in turn activates anti-inflammatory transforming growth factor $\beta$ [34]. CO also provided protection against endotoxic shock via reciprocal effects on the inducible nitrous oxide synthase pathway in the lung and liver [35]. Finally, in the case of vascular smooth muscle and neuronal cell stress, $\mathrm{CO}$ is believed to exert its effects via increases in cyclic guanosine monophosphate signaling [36, 37]. The antiproliferative effects of HO-1 and CO in smooth muscle cells appear to be mediated via caveolin-1, the major structural protein of caveolae which are key components of endocytosis in cells such as lung endothelial cells, type I pneumocytes, (murine) alveolar macrophages and fibroblasts [38]; this pathway is also being explored vis á vis ventilator-induced lung injury [39].

Though it is clear that many of the cell's most central signaling cascades are involved, precise molecular mechanisms are unknown to date and $\mathrm{HO}-1$ signaling interactions appear to be highly situational. Analysis of $\mathrm{HO}-1$ and $\mathrm{CO}$ pathways is further complicated by the extensive redundancy of cellular danger and damage signaling. What seems most apparent is the unifying theme of reactive oxygen species as a critical trigger to $\mathrm{HO}-1$ induction and the ability of its product, $\mathrm{CO}$, to abrogate the deleterious effects of an overexuberant inflammatory response via stimulation of cytoprotective and antiapoptotic pathways. This ambiguous and complex interplay of injury models, cellular stress, signaling molecules, and HO-1 and its product $\mathrm{CO}$ are depicted in Figure 2.

\section{Sepsis Models: Lipopolysaccharide Endotoxemia and Polymicrobial Sepsis}

The experimental models discussed below emulate both gram-negative sepsis and associated ALI. Sepsis itself may be an important target for CO therapy. And, in the case of systemically administered LPS, the associated lung injury mimics the ARDS we often see in septic patients as a secondary inflammatory injury. Intranasal and intratracheal LPS administration create direct lung tissue injury, apoptosis, and necrosis, as would be seen in infectious pneumonia [40].

Early investigations into sepsis-related HO-1 effects revealed that $\mathrm{HO}-1$ is induced in vitro and in vivo in response to a variety of oxidative stresses. Intravenous LPS administration of $0.1 \mathrm{mg} / \mathrm{kg}$ in a mouse model resulted in transcriptional upregulation of HO-1 in the kidney, liver, and spleen [41]; similarly, intravenous LPS administration of $4 \mathrm{mg} / \mathrm{kg}$ in a rat model revealed induction of HO-1 in the smooth muscle of large and small arteries [42]. HO-1 is also upregulated in the lung tissue of rats following LPS exposure [43]. Importantly, HO-1 induction appears to confer tremendous protection against oxidative stress as demonstrated by Otterbein et al. in work exploring a rat model of sepsis. In this series, rats were pretreated with hemoglobin in order to induce HO-1. Following pretreatment, a lethal dose of LPS was administered. When compared to rats not exposed to hemoglobin, the pretreated rats had $100 \%$ survival [43]. Kanagawa et al. demonstrated hepatic growth factor dependent HO-1 induction in an intraperitoneal LPS injection rat model; they further demonstrated diminished lung and kidney injury following LPS insult for HO-1 induced animals [44].

Given that $\mathrm{CO}$ is one of three cellular products of HO-1 and a potential downstream mediator of HO-1 effects, the possibility that $\mathrm{CO}$ could functionally replace $\mathrm{HO}-1$ has been explored [36]. CO abrogated LPS induction of proinflammatory cytokines tumor necrosis factor $\alpha$ (TNF- $\alpha$ ), IL- $1 \beta$, and macrophage inflammatory protein (MIP)- $1 \beta$ and augmented LPS induction of anti-inflammatory IL-10 $[36,45]$. Expansion of this work demonstrated the beneficial effects of either HO-1 enzyme induction or exogenous $\mathrm{CO}$ in abrogating inflammatory and apoptotic pathways following LPS challenge. Within 24 hours after intratracheal administration of LPS in mice, epithelial cell injury and apoptosis in lung macrophages, neutrophils, and alveolar wall can be detected. CO preconditioning with $250 \mathrm{ppm}$ reduced TNF- $\alpha$, IL- $1 \beta$, IL-6, and the aforementioned injury and apoptosis $[36,46]$. 


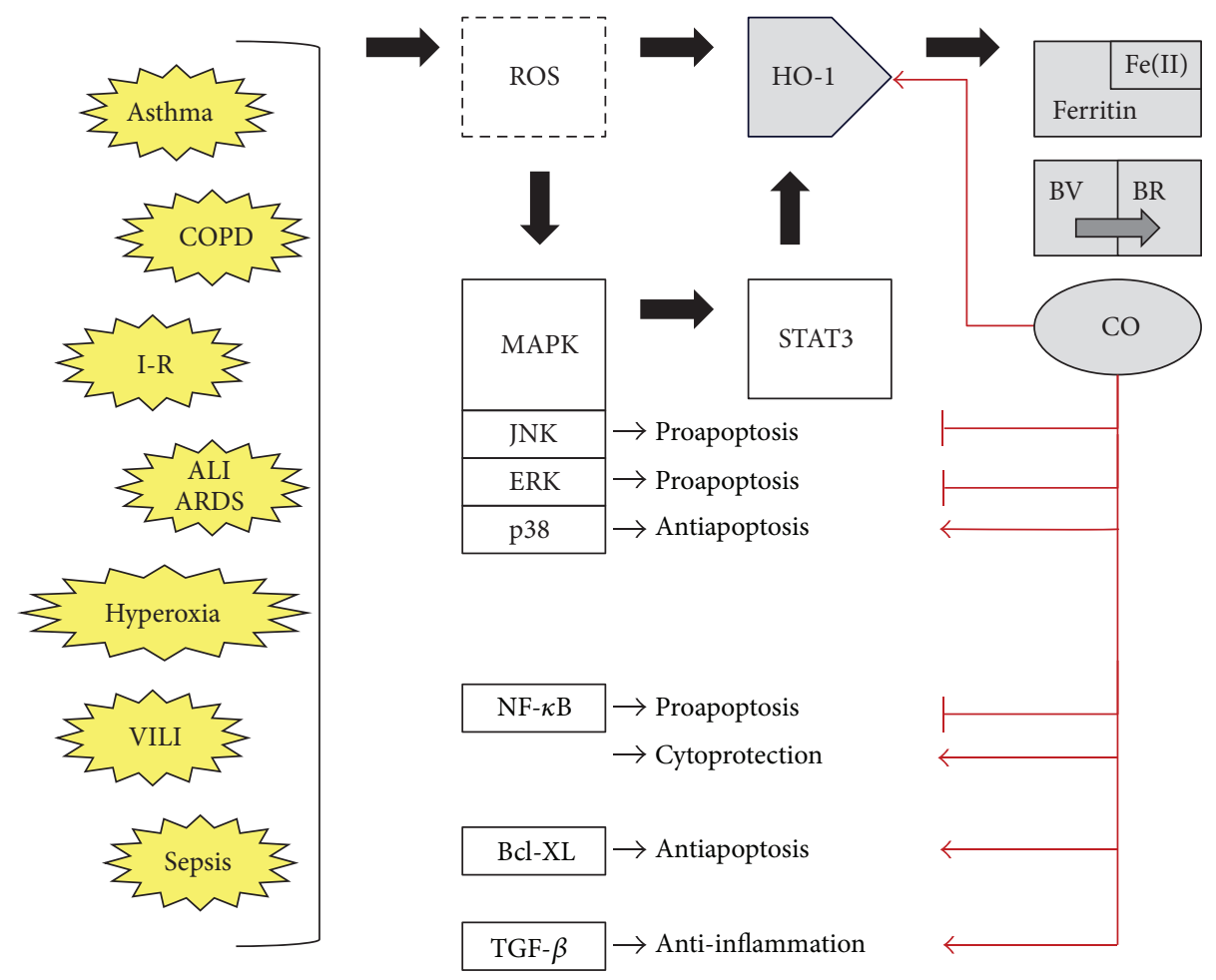

FIGURE 2: Summary of oxidative stress triggers and HO-1 related cellular responses. BV: biliverdin, BR: bilirubin; otherwise abbreviations are as defined in the text. Oxidative stresses trigger ROS which in turn trigger the MAPK pathway as well as HO-1 via MAPK dependent and independent mechanisms. MAPK further signals through STAT3 to upregulate HO-1 transcription. HO-1 produces free iron which is sequestered into ferritin, biliverdin which is converted into bilirubin, and $\mathrm{CO}$ which is stable and diffuses readily. CO production further increases $\mathrm{HO}-1$ levels. In addition, $\mathrm{CO}$ influences multiple other signaling pathways to decrease apoptosis and inflammation.

Sepsis survival in a murine Staphylococcus aureus model was significantly enhanced using inhaled CO, 250 ppm daily for 1 hour, and linked mechanistically to $\mathrm{HO}-1$ induction and mitochondrial HO activity through NF-E2-related factor-2 and Akt kinase [47].

LPS sepsis models are helpful as mimics of the host inflammatory response to infection which is often a driving force behind the pathophysiology of clinical sepsis. However, there is possible harm in blunting an inflammatory response designed to facilitate microbial clearance. In a series of suggestive experiments by Chung et al., utilizing a cecal ligation-puncture (CLP) murine model, it was noted that HO-1 deficient mice had increased gastrointestinal tissue destruction, higher mortality and higher levels of bacteremia. In contrast, mice with HO-1 overexpression targeted to vascular smooth muscle cells had improved mortality, and lower levels of bacteremia. When the authors compared survival in HO-1 overexpressing mice after induction of single species bacteremia, it was noted that $\mathrm{HO}-1$ was protective in the case of Enterococcus faecalis bacteremia but not in the case of Escherichia coli bacteremia. The survival benefit of HO-1 overexpression was then recapitulated with CO-RM administration before and after CLP surgery [48]. Works by $\mathrm{Su}$ et al. and Otterbein et al. suggest that at least part of the role of CO in bacterial clearance is related to increased bacterial phagocytosis [48, 49]. Furthermore, when CO is delivered via CO-RM, we also see increased in vitro bacterial killing (Escherichia coli and Pseudomonas aeruginosa) and abrogation of the sepsis insult in murine and rat experiments utilizing LPS and CLP sepsis models [50-54].

In a related analysis of endogenous $\mathrm{CO}$, it was noted that in septic human patients $\mathrm{HO}-1$ expression as well as $\mathrm{CO}$ production was elevated in comparison to nonseptic critically ill patients [55]. More interestingly, it appears that survivors of sepsis had higher endogenous CO levels versus nonsurvivors [55]. Though we are lacking the definitive experiments which combine true polymicrobial sepsis and gaseous CO administration, the above mentioned work does suggest that $\mathrm{CO}$ may be therapeutically successful. We still lack data in septic or ALI/ARDS patients as to the safety or efficacy of CO in these critically ill patients. Prior to human studies, additional preclinical studies on large and small animal models are warranted, as discussed below.

\section{Hyperoxia and Ventilator-Induced Lung Injury Models}

ALI and ARDS are often a result of the inflammatory cascade triggered by intrinsic disease or an iatrogenic syndrome caused by the oxygen and mechanical ventilation physicians deliver to support tissue oxygenation. Experimental studies exploring the utility of $\mathrm{CO}$ administration during mechanical ventilation or during hyperoxygenation may become realistic 
if safe modes of delivery and therapeutic doses were established.

The lung damage resulting from hyperoxia exposure occurs predominantly in the respiratory endothelium (vessel lining) and epithelium (airway lining) [56]. Rats and mice exposed to hyperoxia ( $>95 \%$ oxygen) develop lung inflammation characterized by neutrophil influx, pulmonary edema, pleural effusion, and increased lung cell apoptotic markers. HO-1 is known to be increased in such models [56]. As a mimic of HO-1 overexpression, the concurrent delivery of $\mathrm{CO}$ at a concentration of $250 \mathrm{ppm}$ in the hyperoxic environment prolongs survival of rats and mice subjected to a lethal dose of hyperoxia. $\mathrm{CO}$ administration also reduces histologic markers of lung injury such as neutrophil infiltration, fibrin deposition, alveolar proteinosis, pulmonary edema, and total apoptotic index. Mice subjected to this injury model were noted to have decreased expression of proinflammatory cytokines including TNF- $\alpha$, IL-1 $\beta$, and IL- 6 [57]. Furthermore, hyperoxia and the resultant HO-1 increase are associated with activated MAPK in lung tissue. The protection by $\mathrm{CO}$ was dependent in this case on $\mathrm{p} 38 \beta \mathrm{MAPK}$ and its upstream regulator mitogen activated protein kinase kinase 3 (MKK3) [45, 57]. It was also demonstrated that endothelial signal transducer and activator of transcription (STAT3) is essential for the protective effects of $\mathrm{CO}$ and HO1 in oxidant induced lung injury and apoptosis [58]. Finally, it was shown in mouse lung endothelial cells exposed to hyperoxia that a low dose of $\mathrm{CO}$ at $250 \mathrm{ppm}$ inhibited the initiation and propagation of extrinsic apoptosis pathways. The protective effect of $\mathrm{CO}$ in this model was dependent on ERK1/ERK2 MAPK [59].

Mechanical ventilation, even in the case of normoxia (21\% oxygen), can induce ventilator-induced lung injury (VILI). Rat models of VILI utilizing co-administration of LPS and carbon monoxide demonstrated that $\mathrm{CO}$ was protective in this combined model of sepsis and lung injury. The protective effect was via a p38 MAPK pathway and independent of activator protein-1 and NF- $\kappa \mathrm{B}$ pathways [60]. A murine model of VILI which coadministered $250 \mathrm{ppm}$ CO evaluated parameters of injury such as bronchial alveolar lavage (BAL) total protein, total cell count, and neutrophil count as well as induction of HO-1 and heat shock protein -70 in lung tissue. Though VILI generally results in increases in these parameters, the use of $\mathrm{CO}$ resulted in a decrease towards normal levels of BAL total protein, cell count and neutrophil count. $\mathrm{CO}$ also abolished early expression of the proinflammatory early growth response-1 protein and the cytoprotection by $\mathrm{CO}$ was dependent on the peroxisome proliferator-activated receptor protein- $\gamma$, an anti-inflammatory nuclear regulator [61]. Finally, consistent with the findings in smooth muscle relating the effects of CO to caveolin-1 and p38 MAPK [38], Hoetzel et al. demonstrated that CO protection in VILI is also dependent on caveolin-1 [39]. In contrast to the initiation of sepsis, which occurs at varying time points prior to clinical intervention, the fact that we control the initiation of mechanical ventilation and hyperoxia creates a unique window of therapeutic opportunity to concurrently initiate $\mathrm{CO}$ administration and perhaps more readily translate these experimental findings into benefits for critically ill patients.

\section{Ischemia-Reperfusion Models}

Cytotoxic ROS produced during ischemia-reperfusion (I-R) insult to the lung promote the recruitment of inflammatory leukocytes and cause lung injury and cell death secondary to both necrosis and apoptosis. Lung I-R injury (or anoxiareoxygenation (A-R) injury in cells) is a model of transplantinduced tissue injury. Endothelial cells represent the primary target for ROS dependent injury. In a series of supporting experiments, $\mathrm{HO}-1^{-/-}$mice were shown to be highly susceptible to lung I-R injury; as we might expect, $\mathrm{CO}$ can overcome this genetic susceptibility $[62,63]$. A generalized understanding of the interaction between $\mathrm{CO}$ and I-R injury models is available from a wide variety of studies in other organ systems such as gut $[64,65]$, liver $[66,67]$, kidney [68$70]$, and heart [71, 72].

Our laboratory has used both mouse lung I-R injury as well as endothelial cell A-R injury to demonstrate that $\mathrm{CO}$ has potent anti-inflammatory and anti-apoptotic effects [26, 27]. In complementary studies of A-R in primary rat pulmonary artery endothelial cells and I-R injury to mouse lung, we noted the induction of caspase 3-dependent apoptosis by A-R or I-R. Treatment with CO diminished apoptosis in both models via a p38 MAPK-dependent pathway [27]. Expansion of this work demonstrated that $\mathrm{CO}$ activates the p38 $\alpha$ MAPK isoform, and its upstream MAPK kinase MKK3, which modulates Fas-mediated cell death [26].

In a larger animal I-R model, miniature swine underwent left pulmonary artery and vein clamping for 90 minutes with or without $250 \mathrm{ppm}$ CO supply during the procedure. The $\mathrm{CO}$ exposed group showed increased arterial oxygen tension, fewer pathologic radiographic findings, and decreased histologic markers of pathologic change at autopsy. BAL analysis revealed decreased inflammatory cell infiltrates (including neutrophils) and serum analysis demonstrated decreased inflammatory markers of IL- $1 \beta$ and IL- 6 and high mobility box group-1 [73].

In a transplant model of I-R, CO (500 ppm) delivered at the end of a syngeneic orthotopic lung transplant in rats until a follow-up time of up to 6 days demonstrated CO mediated cytoprotection via anti-inflammatory action (downregulation of IL-6, MIP- $1 \alpha$ and macrophage migration inhibitory factor). Anti-apoptotic effects in lung macrophages, endothelial, and epithelial cells were also observed [27]. Rat lung syngeneic transplant protection via $250 \mathrm{ppm}$ CO delivered at timed intervals before and continuously after lung surgery demonstrated better graft function, as measured by partial pressure of oxygen, reduced neutrophil infiltration, maintenance of cellular ultrastructure, and reduced IL-6, IL-1 $\beta$, TNF- $\alpha$, inducible nitric oxide synthase, cyclooxygenase- 2 , and intracellular adhesion molecule-1. The CO effect in this model was NF- $\kappa$ B independent and changes in IL-10 or HO-1 levels were not observed [74].

\section{Complex and Large Animal Models}

Several investigators have expanded the aforementioned work by creating large animal models and more complex clinical models. Dolinay et al. created a rat model in which 
combined insults of endotoxemia (via LPS) and VILI were administered in a stepwise lung injury model designed to mimic the common scenario of the intubated septic patient. Analysis of rat lungs, which had sequentially been exposed to $3 \mathrm{mg} / \mathrm{kg}$ intravenous LPS and then mechanical ventilation with tidal volumes of $12 \mathrm{~mL} / \mathrm{kg}$, revealed increased total protein, TNF- $\alpha$, macrophages, and neutrophils in BAL fluid. Treatment with 100 and $250 \mathrm{ppm}$ of CO concomitant to the ventilator injury revealed reductions in many of the above parameters as well as increases in the anti-inflammatory cytokine IL-10 and p38 MAPK activation [60].

Similar to systemic LPS, hind limb I-R with resultant small intestine inflammation has been used as a model of secondary organ damage in response to distant tissue injury. In this system, $250 \mathrm{ppm}$ of $\mathrm{CO}$ administered at the time of limb reperfusion decreased ICAM- 1 and TNF- $\alpha$ expression and diminished ICAM-1 dependent leukocyte adhesion as compared to the levels normally seen following I-R injury. Because it leads to severe intestinal injury and further inflammatory response, ICAM-1 dependent leukocyte venule adhesion in the small bowel is thought to be a gateway pathway to systemic inflammatory responses and multiorgan dysfunction [75].

Cynomolgus macaques exposed to LPS inhalation and either 250 or $500 \mathrm{ppm}$ CO for 6 hours had some indications of reduction in airway inflammation. These reductions paralleled results seen with inhaled corticosteroid treatment (budesonide) as an established standard for airway anti-inflammatory treatment. Pulmonary neutrophilia was decreased by $500 \mathrm{ppm}$ of CO. BAL fluid TNF- $\alpha$ was decreased by the $500 \mathrm{ppm}$ of CO while IL- 6 and IL- 8 levels were unchanged. In comparison, $250 \mathrm{ppm} \mathrm{CO}$ had no effect on TNF- $\alpha$, IL-6, or IL-8 [76].

Several studies in porcine models have shown the benefit of inhaled $\mathrm{CO}$ in treating endotoxemic shock induced by intravenous administration of LPS. Mazzola et al. administered LPS $40 \mu \mathrm{g} / \mathrm{kg} / \mathrm{hour}$ to large white pigs (swine) for four hours with and without one hour of CO pretreatment (250 ppm). Their combined studies demonstrated the ability of $\mathrm{CO}$ to improve lung mechanics as measured by airway resistance and parenchymal compliance; pulmonary edema was also decreased by $\mathrm{CO}$ inhalation. Furthermore, extrapulmonary organ effects of LPS were mitigated including preservation of heart stroke volume, kidney function, and liver function. Parameters of disseminated intravascular coagulation were decreased by $\mathrm{CO}$ pretreatment. Finally, CO decreased levels of proinflammatory IL- $1 \beta$ and increased levels of anti-inflammatory IL-10 [77, 78]. The major limitation of this work is the use of $\mathrm{CO}$ as a pretreatment which brings into question the clinical relevance for critical care as our opportunity to intervene is virtually always following the onset of shock. This limitation is addressed by Koulouras et al. in which pigs received inhaled CO starting 2.5 hours after the initiation of an intravenous LPS administration $(20 \mu \mathrm{g} / \mathrm{kg} /$ hour for 2.5 hours then $10 \mu \mathrm{g} / \mathrm{kg} / \mathrm{hour}$ for 3.5 hours). In these studies, a broad variety of cardiovascular parameters were monitored; LPS-induced increase in pulmonary artery pressure was the only parameter significantly altered by $\mathrm{CO}$ administration though there was a trend towards improvement in pulmonary vascular resistance. There were no changes in inflammatory markers with and without $\mathrm{CO}$ administration but there were however significant changes in alveolar cellular infiltration, edema, and hemorrhage [79]. Thus, studies using large and small animals demonstrate a trend towards improvement with $\mathrm{CO}$ administration.

\section{Human Studies}

As human studies are initiated, there are significant safety concerns given the somewhat narrow window of carbon monoxide dosing that would be necessary to avoid CO toxicity. Interestingly, safety trials demonstrate that $\mathrm{CO}$ inhalation up to $100 \mathrm{ppm}$ for two hours, $500 \mathrm{ppm}$ for one hour, or even 400 to $1000 \mathrm{ppm}$ for approximately one hour is without adverse event and does not elevate carboxyhemoglobin $(\mathrm{COHb})$ levels above those seen in heavy smokers [4-6]. One of the highest levels of $\mathrm{CO}$ delivered in a phase I trial setting is that of a recent single-blind, randomized, placebo-controlled phase 1 human trial evaluating drug safety and delivery. This trial utilized an investigational device the Covox DS (Ikaria, Clinton, NJ), which delivered $3.0 \mathrm{mg}$ per $\mathrm{kg} \mathrm{CO}$ per hour, for 1 hour given either once or daily for 10 days. $\mathrm{COHb}$ elevated reliably to $12 \%$ and no adverse effects were reported [7]. New CO delivery systems such as this one lend feasibility to future therapeutic trials with $\mathrm{CO}$. CO delivery to critically ill patients on mechanical ventilation poses special challenges as well, given the potential devastating consequences of $\mathrm{CO}$ leaks to patients and staff.

Brief dosing of CO at $500 \mathrm{ppm}$ for one hour after LPS administration to healthy human volunteers did not abrogate LPS-induced inflammatory responses, as indicated by no differences in plasma C-reactive protein, neutrophil count, TNF- $\alpha$, IL-6, or IL-10. It seems likely that differences in CO binding, diffusion, and ultimately tissue delivery may account for the discrepancy between compelling mouse data using $250 \mathrm{ppm}$ of $\mathrm{CO}$ and negative human data with $500 \mathrm{ppm}$ of $\mathrm{CO}$ [4]. Notably parameters such as $\mathrm{COHb}$ vary between this study in humans (maximal COHb of 7.0\%) [4] and a similar study in pigs (maximal $\mathrm{COHb}$ of $14.1 \%$ ) [77]. However, studies using $\mathrm{COHb}$ as indicator of $\mathrm{CO}$ levels are limited by the fact that $\mathrm{COHb}$ does not reflect tissue $\mathrm{CO}$ levels and endogenous $\mathrm{HO} / \mathrm{CO}$ activity nor is it predictive of $\mathrm{CO}$ toxicity [80].

Asthma is characterized by chronic airway inflammation; there has been well-justified interest in exploring the possibility that CO may have a therapeutic role for asthma patients. Murine asthma models using ova-albumin sensitization have improved BAL inflammatory cell counts (eosinophils and macrophages) when treated with $\mathrm{CO}$. Exogenous $\mathrm{CO}$ administration reduced IL-5, proinflammatory mediators interferon- $\gamma$, leukotriene B4, and prostaglandin E2 [81]. Follow-up studies with a single 10-minute exposure to $\mathrm{CO}$ at 500 to $1000 \mathrm{ppm}$ reduced methacholine-induced airway resistance in ova-albumin challenged mice as did repeated administration of low-dose CO $250-500$ ppm over a 5-day period [82]. Observational human studies have suggested elevated levels of exhaled $\mathrm{CO}$ in nonsmoking asthmatics 
as compared to healthy control subjects [83] and there has been some suggestion that exhaled CO may have a role in characterizing asthma disease severity.

Patients with COPD are postulated to have disease progression related to a relative lack in $\mathrm{HO}-1 / \mathrm{CO}$ production relative to their non-COPD, smoking counterparts $[84,85]$. Therefore, in a phase II clinical trial, Bathoorn et al. explored the efficacy of $\mathrm{CO}$ administration in abrogating the chronic airway inflammation that characterizes COPD. Administration of between 100 and 125 ppm for 2 hours on 4 consecutive days was safe with a maximal $\mathrm{COHb}$ level of $4.5 \%$ and led to a trend in reduction of airway responsiveness, as characterized by methacholine challenge, and a trend towards less sputum eosinophils [84]. In a similar example of what is believed to be a disease of chronic inflammation, a phase II trial of 100 to $200 \mathrm{ppm}$ inhaled CO for two hours twice weekly for twelve weeks is being initiated in idiopathic pulmonary fibrosis patients; outcomes will include serum biomarkers of idiopathic pulmonary fibrosis, functional lung studies, and symptom questionnaires (NCT01214187).

\section{Discussion}

There may be therapeutic potential to CO-based interventions. The pleiotropic effects of $\mathrm{CO}$ in abrogating inflammation and apoptosis, and thus protecting against an array of cellular insults, suggest a great opportunity to intervene in multiple critical care illnesses-sepsis, ischemia, and ALI. We have extensive in vitro and in vivo evidence of the protective effects of CO. However, the field has not yet defined the precise pathways of $\mathrm{CO}$ action, raising a lurking concern that this therapy could have unexpected effects. The historical categorization of $\mathrm{CO}$ gas as a poison and the knowledge that it can be harmful at high doses bring this concern further to the fore. Despite success at safe doses of 250 to $500 \mathrm{ppm}$ in rodent models, success in higher mammals and humans has been limited.

The amount of $\mathrm{CO}$ inhaled and/or exposure time are the most critical factors that determine the severity of $\mathrm{CO}$ toxicity. Administering inhaled $\mathrm{CO}$ poses challenges in controlling the absorption, distribution, and tissue targeting of $\mathrm{CO}$. The characterization and implementation of $\mathrm{CO}$ carriers $(\mathrm{CO}-$ $\mathrm{RMs}$ ) that deliver $\mathrm{CO}$ in a more controlled fashion may open opportunities for the design of CO-based pharmaceuticals in the future [86]. In addition, children and older adults are more susceptible to CO toxicity and may have more severe symptoms [87]. Predisposing conditions for CO toxicity have also been described, such as cardiovascular disease, COPDs or anemia [88]. Conceivably, ALI/ARDS patients, who already exhibit hypoxia and poor tissue oxygenation, would be even more susceptible to CO toxicity, even at low doses. Therefore, careful tailoring to different patient populations would be necessary if $\mathrm{CO}$ were to be used as a therapy. Dose ranges and kinetics have not been adequately assessed but should be areas of active inquiry. It may be that we have to return to phase I safety trials at higher $\mathrm{CO}$ doses or advance our delivery methods to attain higher $\mathrm{CO}$ concentrations in a given target organ.
Furthermore, we must consider the double-edged sword of a therapeutic entity that has such broad, potentially toxic, effects. There are valid concerns that blunting an inflammatory response, while beneficial in a sterile laboratory model of sepsis such as LPS administration, may be harmful in true infection and/or polymicrobial sepsis. These concerns are somewhat allayed by CLP- and CO-RM utilizing models which demonstrate not only benefit vis á vis blunted inflammatory response but also the promotion of bactericidal activity directly by $\mathrm{CO}$, but there is more work to be done in defining this aspect of $\mathrm{CO}$.

Another concern is the timing of $\mathrm{CO}$ administration, which in the well-developed transplant literature occurs before insult. This timing is not practical in critically ill patients because we cannot anticipate onset of severe illness. However, there is a growing body of research showing that co-administration and post-insult $\mathrm{CO}$ administration are effective. This is notable in the VILI literature in which $\mathrm{CO}$ can be administered during mechanical ventilation, which is the most likely scenario in critical care medicine. Notably, delayed CO administration, but not pretreatment, was beneficial in a mouse model of VILI [89]. Furthermore, the transplant literature has extended its studies and demonstrated benefit even in the setting of significantly delayed CO administration [90].

Nonetheless, $\mathrm{CO}$ administration is a novel and intriguing modality with great potential, if applied judiciously. CO therapy for critically ill patients suffering from lung injury, multiorgan failure, or organ transplantation rejection may yield results not previously attained in this exceptionally ill population. Compelling basic science investigations justify expanding $\mathrm{CO}$ to the clinical realm in the form of clinical trials. However, the specific cellular response to $\mathrm{CO}$ requires further elucidation and testing of $\mathrm{CO}$ in disease-specific animal models.

\section{Abbreviations}

ALI: Acute lung injury

A-R: Anoxia-reoxygenation

ARDS: Acute respiratory distress syndrome

BAL: Bronchial alveolar lavage

Bcl-2: B-cell lymphoma-2

CLP: Cecal ligation and puncture

CO: $\quad$ Carbon monoxide

COHb: Carboxyhemoglobin

COPD: Chronic obstructive pulmonary disease

CO-RM: Carbon monoxide releasing molecule

ERK: Extracellular signal-regulated kinase

HO-1: Heme oxygenase-1

IL: Interleukin

I-R: Ischemia-reperfusion

JNK: c-Jun $\mathrm{NH}_{2}$-terminal protein kinase

LPS: Lipopolysaccharide

MAPK: Mitogen-activated protein kinase

MIP: Macrophage inflammatory protein

MKK3: Mitogen activated protein kinase kinase 3

NF- $\kappa$ B: Nuclear factor-kappa-light-chain enhancer of activated B cells 
PPM: $\quad$ Parts per million

PI3K/Akt: Phosphatidylinositol-3-kinase

ROS: $\quad$ Reactive oxygen species

STAT3: Signal transducer and activator of transcription 3

TNF- $\alpha$ : Tumor necrosis factor

VILI: Ventilator induced lung injury.

\section{References}

[1] J. Zhang, X. Yao, R. Yu et al., "Exhaled carbon monoxide in asthmatics: a meta-analysis," Respiratory Research, vol. 11, article 50.

[2] P. Paredi, P. L. Shah, P. Montuschi et al., "Increased carbon monoxide in exhaled air of patients with cystic fibrosis," Thorax, vol. 54, no. 10, pp. 917-920, 1999.

[3] S. Ghosh, J. Gal, and N. Marczin, "Carbon monoxide: endogenous mediator, potential diagnostic and therapeutic target," Annals of Medicine, vol. 42, no. 1, pp. 1-12, 2010.

[4] F. B. Mayr, A. Spiel, J. Leitner et al., "Effects of carbon monoxide inhalation during experimental endotoxemia in humans," American Journal of Respiratory and Critical Care Medicine, vol. 171, no. 4, pp. 354-360, 2005.

[5] J. E. Peterson and R. D. Stewart, "Absorption and elimination of carbon monoxide by inactive young men," Archives of Environmental Health, vol. 21, no. 2, pp. 165-171, 1970.

[6] A. Takeuchi, A. Vesely, J. Rucker et al., "A simple, "new" method to accelerate clearance of carbon monoxide," American Journal of Respiratory and Critical Care Medicine, vol. 161, no. 6, pp. 1816-1819, 2000.

[7] R. Motterlini and L. E. Otterbein, "The therapeutic potential of carbon monoxide," Nature Reviews Drug Discovery, vol. 9, no. 9, pp. 728-743, 2010.

[8] E. Allen, "Properties and reactions of carbon monoxide," in Carbon Monoxide, pp. 4-27, National Research Council (Subcommittee on Carbon Monoxide). National Academy of Sciences, 1977.

[9] D. F. Shriver, Activation of Carbon Monoxide by Carbon and Oxygen Coordination, American Chemical Society, Washington, DC, USA, 1981.

[10] R. F. Coburn, "The carbon monoxide body stores," Annals of the New York Academy of Sciences, vol. 174, no. 1, pp. 11-22, 1970.

[11] M. D. Maines, "The heme oxygenase system: a regulator of second messenger gases," Annual Review of Pharmacology and Toxicology, vol. 37, pp. 517-554, 1997.

[12] C. A. Piantadosi, "Biological chemistry of carbon monoxide," Antioxidants and Redox Signaling, vol. 4, no. 2, pp. 259-270, 2002.

[13] T. Santos-Silva, A. Mukhopadhyay, J. D. Seixas, G. J. L. Bernardes, C. C. Romão, and M. J. Romão, “Towards improved therapeutic CORMs: understanding the reactivity of CORM-3 with proteins," Current Medicinal Chemistry, vol. 18, no. 22, pp. 3361-3366, 2011.

[14] C. C. Romao, W. A. Blättler, J. D. Seixas, and G. J. L. Bernardes, "Developing drug molecules for therapy with carbon monoxide," Chemical Society Reviews, vol. 41, no. 9, pp. 3571-3583, 2012.

[15] V. Y. Dombrovskiy, A. A. Martin, J. Sunderram, and H. L. Paz, "Rapid increase in hospitalization and mortality rates for severe sepsis in the United States: a trend analysis from 1993 to 2003," Critical Care Medicine, vol. 35, no. 5, pp. 1244-1250, 2007.
[16] D. C. Angus, W. T. Linde-Zwirble, J. Lidicker, G. Clermont, J. Carcillo, and M. R. Pinsky, "Epidemiology of severe sepsis in the United States: analysis of incidence, outcome, and associated costs of care," Critical Care Medicine, vol. 29, no. 7, pp. 1303-1310, 2001.

[17] A. M. E. Spoelstra - De Man and A. R. J. Girbes, "Comment on "Surviving Sepsis Campaign: international guidelines for management of severe sepsis and septic shock: 2008" by Dellinger et al," Intensive Care Medicine, vol. 34, no. 6, pp. 1160$1162,2008$.

[18] C.-C. Sheu, M. N. Gong, R. Zhai et al., "Clinical characteristics and outcomes of sepsis-related vs non-sepsis-related ARDS," Chest, vol. 138, no. 3, pp. 559-567, 2010.

[19] L. E. Otterbein, B. S. Zuckerbraun, M. Haga et al., "Carbon monoxide suppresses arteriosclerotic lesions associated with chronic graft rejection and with balloon injury," Nature Medicine, vol. 9, no. 2, pp. 183-190, 2003.

[20] F. Amersi, X.-D. Shen, D. Anselmo et al., "Ex vivo exposure to carbon monoxide prevents hepatic ischemia/reperfusion injury through p38 MAP kinase pathway," Hepatology, vol. 35, no. 4, pp. 815-823, 2002.

[21] S. Brouard, L. E. Otterbein, J. Anrather et al., "Carbon monoxide generated by heme oxygenase 1 suppresses endothelial cell apoptosis," Journal of Experimental Medicine, vol. 192, no. 7, pp. 1015-1025, 2000

[22] M. Desmard, N. Amara, S. Lanone, R. Motterlini, and J. Boczkowski, "Carbon monoxide reduces the expression and activity of matrix metalloproteinases 1 and 2 in alveolar epithelial cells," Cellular and Molecular Biology, vol. 51, no. 4, pp. 403408, 2005.

[23] M. Constantin, A. J. S. Choi, S. M. . Cloonan, and S. W. Ryter, "Therapeutic potential of heme oxygenase-1/carbon monoxide in lung disease," International Journal of Hypertension, vol. 2012, Article ID 859235, 19 pages, 2012.

[24] W. Ning, A. M. K. Choi, and C. Li, "Carbon monoxide inhibits IL-17-induced IL-6 production through the MAPK pathway in human pulmonary epithelial cells," American Journal of Physiology: Lung Cellular and Molecular Physiology, vol. 289, no. 2, pp. L268-L273, 2005.

[25] B. S. Zuckerbraun, B. Y. Chin, M. Bilban et al., "Carbon monoxide signals via inhibition of cytochrome $\mathrm{c}$ oxidase and generation of mitochondrial reactive oxygen species," The FASEB Journal, vol. 21, no. 4, pp. 1099-1106, 2007.

[26] X. Zhang, P. Shan, J. Alam, R. J. Davis, R. A. Flavell, and P. J. Lee, "Carbon monoxide modulates Fas/Fas ligand, caspases, and Bcl-2 family proteins via the $\mathrm{p} 38 \alpha$ mitogen-activated protein kinase pathway during ischemia-reperfusion lung injury," The Journal of Biological Chemistry, vol. 278, no. 24, pp. 2206122070, 2003.

[27] R. Song, M. Kubo, D. Morse et al., "Carbon monoxide induces cytoprotection in rat orthotopic lung transplantation via antiinflammatory and anti-apoptotic effects," American Journal of Pathology, vol. 163, no. 1, pp. 231-242, 2003.

[28] M. A. Arruda, A. G. Rossi, M. S. De Freitas, C. Barja-Fidalgo, and A. V. Graça-Souza, "Heme inhibits human neutrophil apoptosis: involvement of phosphoinositide 3-kinase, MAPK, and NF- $\kappa \mathrm{B}$," Journal of Immunology, vol. 173, no. 3, pp. 20232030, 2004.

[29] X. Zhang, P. Shan, J. Alam, X.-Y. Fu, and P. J. Lee, "Carbon monoxide differentially modulates STAT1 and STAT3 and inhibits apoptosis via a phosphatidylinositol 3-kinase/Akt 
and p38 kinase-dependent STAT3 pathway during anoxiareoxygenation injury," The Journal of Biological Chemistry, vol. 280, no. 10, pp. 8714-8721, 2005.

[30] K. R. Brunt, K. K. Fenrich, G. Kiani et al., "Protection of human vascular smooth muscle cells from $\mathrm{H}_{2} \mathrm{O}_{2}$-induced apoptosis through functional codependence between HO-1 and AKT," Arteriosclerosis, Thrombosis, and Vascular Biology, vol. 26, no. 9, pp. 2027-2034, 2006.

[31] R. Gozzelino, V. Jeney, and M. P. Soares, "Mechanisms of cell protection by heme oxygenase-1," Annual Review of Pharmacology and Toxicology, vol. 50, pp. 323-354, 2010.

[32] L. Conde de la Rosa, T. E. Vrenken, R. A. Hannivoort et al., "Carbon monoxide blocks oxidative stress-induced hepatocyte apoptosis via inhibition of the p54 JNK isoform," Free Radical Biology and Medicine, vol. 44, no. 7, pp. 1323-1333, 2008.

[33] M. P. Soares, M. P. Seldon, I. P. Gregoire et al., "Heme oxygenase1 modulates the expression of adhesion molecules associated with endothelial cell activation," Journal of Immunology, vol. 172, no. 6, pp. 3553-3563, 2004.

[34] B. Y. Chin et al., "Hypoxia-inducible factor lalpha stabilization by carbon monoxide results in cytoprotective preconditioning," Proceedings of the National Academy of Sciences of the United States of America, vol. 104, no. 12, pp. 5109-5114, 2007.

[35] J. K. Sarady, B. S. Zuckerbraun, M. Bilban et al., "Carbon monoxide protection against endotoxic shock involves reciprocal effects on iNOS in the lung and liver," The FASEB Journal, vol. 18, no. 7, pp. 854-856, 2004.

[36] L. E. Otterbein, F. H. Bach, J. Alam et al., "Carbon monoxide has anti-inflammatory effects involving the mitogen- activated protein kinase pathway," Nature Medicine, vol. 6, no. 4, pp. 422428, 2000.

[37] T. Morita, M. A. Perrella, M.-E. Lee, and S. Kourembanas, "Smooth muscle cell-derived carbon monoxide is a regulator of vascular cGMP," Proceedings of the National Academy of Sciences of the United States of America, vol. 92, no. 5, pp. 1475-1479, 1995.

[38] H. P. Kim, X. Wang, A. Nakao et al., "Caveolin-1 expression by means of $\mathrm{p} 38 \beta$ mitogen-activated protein kinase mediates the antiproliferative effect of carbon monoxide," Proceedings of the National Academy of Sciences of the United States of America, vol. 102, no. 32, pp. 11319-11324, 2005.

[39] A. Hoetzel, R. Schmidt, S. Vallbracht et al., "Carbon monoxide prevents ventilator-induced lung injury via caveolin-1," Critical Care Medicine, vol. 37, no. 5, pp. 1708-1715, 2009.

[40] G. Matute-Bello, C. W. Frevert, and T. R. Martin, "Animal models of acute lung injury," American Journal of Physiology: Lung Cellular and Molecular Physiology, vol. 295, no. 3, pp. L379-L399, 2008.

[41] S. Oshiro, H. Takeuchi, M. Matsumoto, and S.-I. Kurata, "Transcriptional activation of heme oxygenase-1 gene in mouse spleen, liver and kidney cells after treatment with lipopolysaccharide or hemoglobin," Cell Biology International, vol. 23, no. 7, pp. 465-474, 1999.

[42] S.-F. Yet, A. Pellacani, C. Patterson et al., "Induction of heme oxygenase-1 expression in vascular smooth muscle cells. A link to endotoxic shock," The Journal of Biological Chemistry, vol. 272, no. 7, pp. 4295-4301, 1997.

[43] L. Otterbein, S. L. Sylvester, and A. M. Choi, "Hemoglobin provides protection against lethal endotoxemia in rats: the role of heme oxygenase-1," American Journal of Respiratory Cell and Molecular Biology, vol. 13, no. 5, pp. 595-601, 1995.

[44] F. Kanagawa, T. Takahashi, K. Inoue et al., "Protective effect of carbon monoxide inhalation on lung injury after hemorrhagic shock/resuscitation in rats," Journal of Trauma, vol. 69, no. 1, pp. 185-194, 2010.

[45] L. E. Otterbein, S. L. Otterbein, E. Ifedigbo et al., "MKK3 mitogen-activated protein kinase pathway mediates carbon monoxide-induced protection against oxidant-induced lung injury," American Journal of Pathology, vol. 163, no. 6, pp. 2555$2563,2003$.

[46] D. Morse, S. E. Pischke, Z. Zhou et al., "Suppression of inflammatory cytokine production by carbon monoxide involves the JNK pathway and AP-1," The Journal of Biological Chemistry, vol. 278, no. 39, pp. 36993-36998, 2003.

[47] N. C. MacGarvey, H. B. Suliman, R. R. Bartz et al., "Activation of mitochondrial biogenesis by heme oxygenase-1-mediated NF-E2-related factor-2 induction rescues mice from lethal Staphylococcus aureus sepsis," American Journal of Respiratory and Critical Care Medicine, vol. 185, no. 8, pp. 851-861, 2012.

[48] W. C. Su, X. Liu, A. A. Macias, R. M. Baron, and M. A. Perrella, "Heme oxygenase-1-derived carbon monoxide enhances the host defense response to microbial sepsis in mice," Journal of Clinical Investigation, vol. 118, no. 1, pp. 239-247, 2008.

[49] L. E. Otterbein, A. May, and B. Y. Chin, "Carbon monoxide increases macrophage bacterial clearance through Toll-like receptor (TLR)4 expression," Cellular and Molecular Biology, vol. 51, no. 5, pp. 433-440, 2005.

[50] L. S. Nobre, F. Al-Shahrour, J. Dopazo, and L. M. Saraiva, "Exploring the antimicrobial action of a carbon monoxidereleasing compound through whole-genome transcription profiling of Escherichia coli," Microbiology, vol. 155, part 3, pp. 813824, 2009.

[51] M. Desmard, K. S. Davidge, O. Bouvet et al., "A carbon monoxide-releasing molecule (CORM-3) exerts bactericidal activity against Pseudomonas aeruginosa and improves survival in an animal model of bacteraemia," The FASEB Journal, vol. 23, no. 4, pp. 1023-1031, 2009.

[52] K. S. Davidge, G. Sanguinetti, C. H. Yee et al., "Carbon monoxide-releasing antibacterial molecules target respiration and global transcriptional regulators," The Journal of Biological Chemistry, vol. 284, no. 7, pp. 4516-4524, 2009.

[53] J.-B. Yu and S.-L. Yao, "Effect of heme oxygenase-endogenous carbon monoxide on mortality during septic shock in rats," Irish journal of medical science, vol. 178, no. 4, pp. 491-496, 2009.

[54] S. Lancel, S. M. Hassoun, R. Favory, B. Decoster, R. Motterlini, and R. Neviere, "Carbon monoxide rescues mice from lethal sepsis by supporting mitochondrial energetic metabolism and activating mitochondrial biogenesis," Journal of Pharmacology and Experimental Therapeutics, vol. 329, no. 2, pp. 641-648, 2009.

[55] S. Takaki, N. Takeyama, Y. Kajita et al., "Beneficial effects of the heme oxygenase-1/carbon monoxide system in patients with severe sepsis/septic shock," Intensive Care Medicine, vol. 36, no. 1, pp. 42-48, 2010.

[56] P. J. Lee, J. Alam, S. L. Sylvester, N. Inamdar, L. Otterbein, and A. M. K. Choi, "Regulation of heme oxygenase-1 expression in vivo and in vitro in hyperoxic lung injury," American Journal of Respiratory Cell and Molecular Biology, vol. 14, no. 6, pp. 556568, 1996.

[57] L. E. Otterbein, L. L. Mantell, and A. M. K. Choi, "Carbon monoxide provides protection against hyperoxic lung injury," American Journal of Physiology: Lung Cellular and Molecular Physiology, vol. 276, no. 4, pp. L688-L694, 1999. 
[58] X. Zhang, P. Shan, G. Jiang et al., "Endothelial STAT3 is essential for the protective effects of HO-1 in oxidant-induced lung injury," The FASEB Journal, vol. 20, no. 12, pp. 2156-2158, 2006.

[59] X. Wang, Y. Wang, H. P. Kim, K. Nakahira, S. W. Ryter, and A. M. K. Choi, "Carbon monoxide protects against hyperoxiainduced endothelial cell apoptosis by inhibiting reactive oxygen species formation," The Journal of Biological Chemistry, vol. 282, no. 3, pp. 1718-1726, 2007.

[60] T. Dolinay, M. Szilasi, M. Liu, and A. M. K. Choi, "Inhaled carbon monoxide confers antiinflammatory effects against ventilator-induced lung injury," American Journal of Respiratory and Critical Care Medicine, vol. 170, no. 6, pp. 613-620, 2004.

[61] A. Hoetzel, T. Dolinay, S. Vallbracht et al., "Carbon monoxide protects against ventilator-induced lung injury via PPAR- $\gamma$ and inhibition of Egr-1," American Journal of Respiratory and Critical Care Medicine, vol. 177, no. 11, pp. 1223-1232, 2008.

[62] T. Fujita, K. Toda, A. Karimova et al., "Paradoxical rescue from ischemic lung injury by inhaled carbon monoxide driven by derepression of fibrinolysis," Nature Medicine, vol. 7, no. 5, pp. 598-604, 2001.

[63] S. Mishra, T. Fujita, V. M. Lama et al., "Carbon monoxide rescues ischemic lungs by interrupting MAPK-driven expression of early growth response 1 gene and its downstream target genes," Proceedings of the National Academy of Sciences of the United States of America, vol. 103, no. 13, pp. 5191-5196, 2006.

[64] A. Nakao, B. A. Moore, N. Murase et al., "Immunomodulatory effects of inhaled carbon monoxide on rat syngeneic small bowel graft motility," Gut, vol. 52, no. 9, pp. 1278-1285, 2003.

[65] A. Nakao, K. Kimizuka, D. B. Stolz et al., "Carbon monoxide inhalation protects rat intestinal grafts from ischemia/reperfusion injury," American Journal of Pathology, vol. 163, no. 4, pp. 1587-1598, 2003.

[66] T. Kaizu, A. Ikeda, A. Nakao et al., "Protection of transplantinduced hepatic ischemia/reperfusion injury with carbon monoxide via MEK/ERK1/2 pathway downregulation," American Journal of Physiology: Gastrointestinal and Liver Physiology, vol. 294, no. 1, pp. G236-G244, 2007.

[67] T. Kaizu, A. Nakao, A. Tsung et al., "Carbon monoxide inhalation ameliorates cold ischemia/reperfusion injury after rat liver transplantation," Surgery, vol. 138, no. 2, pp. 229-235, 2005.

[68] J. S. Neto, A. Nakao, K. Kimizuka et al., "Protection of transplant-induced renal ischemia-reperfusion injury with carbon monoxide," American Journal of Physiology: Renal Physiology, vol. 287, no. 5, pp. F979-F989, 2004.

[69] A. Nakao, G. Faleo, H. Shimizu et al., "Ex vivo carbon monoxide prevents cytochrome P450 degradation and ischemia/reperfu$\backslash$ linebreak sion injury of kidney grafts," Kidney International, vol. 74, no. 8, pp. 1009-1016, 2008.

[70] G. Faleo, J. S. Neto, J. Kohmoto et al., "Carbon monoxide ameliorates renal cold ischemia-reperfusion injury with an upregulation of vascular endothelial growth factor by activation of hypoxia-inducible factor," Transplantation, vol. 85, no. 12, pp. 1833-1840, 2008.

[71] Y. Akamatsu, M. Haga, S. Tyagi et al., "Heme oxygenase1-derived carbon monoxide protects hearts from transplant associated ischemia reperfusion injury," The FASEB Journal, vol. 18, no. 6, pp. 771-772, 2004.

[72] A. Nakao, H. Toyokawa, M. Abe et al., "Heart allograft protection with low-dose carbon monoxide inhalation: effects on inflammatory mediators and alloreactive T-cell responses," Transplantation, vol. 81, no. 2, pp. 220-230, 2006.
[73] H. Sahara, A. Shimizu, K. Setoyama et al., "Carbon monoxide reduces pulmonary ischemia-reperfusion injury in miniature swine," Journal of Thoracic and Cardiovascular Surgery, vol. 139, no. 6, pp. 1594-1601, 2010.

[74] J. Kohmoto, A. Nakao, D. B. Stolz et al., "Carbon monoxide protects rat lung transplants from ischemia-reperfusion injury via a mechanism involving p38 MAPK pathway," American Journal of Transplantation, vol. 7, no. 10, pp. 2279-2290, 2007.

[75] J. R. Scott, M. A. Cukiernik, M. C. Ott et al., "Low-dose inhaled carbon monoxide attenuates the remote intestinal inflammatory response elicited by hindlimb ischemia-reperfusion," American Journal of Physiology: Gastrointestinal and Liver Physiology, vol. 296, no. 1, pp. G9-G14, 2009.

[76] L. A. Mitchell, M. M. Channell, C. M. Royer, S. W. Ryter, A. M. Choi, and J. D. McDonald, "Evaluation of inhaled carbon monoxide as an anti-inflammatory therapy in a non-human primate model of lung inflammation," American Journal Of Physiology: Lung Cellular And Molecular Physiology, vol. 299, no. 6, pp. L891-L897.

[77] S. Mazzola, M. Forni, M. Albertini et al., "Carbon monoxide pretreatment prevents respiratory derangement and ameliorates hyperacute endotoxic shock in pigs," The FASEB Journal, vol. 19, no. 14, pp. 2045-2047, 2005.

[78] S. Mazzola, M. Forni, M. Albertini et al., "Inhaled carbon monoxide (CO) prevents lung oedema induced by endotoxic shock," Veterinary Research Communications, vol. 28, no. 1, pp. 209-212, 2004.

[79] V. P. Koulouras, R. Li, L. Chen, and G. G. Hedenstierna, "Effects of inhaled carbon monoxide and glucocorticoids in porcine endotoxin sepsis," International Journal of Clinical and Experimental Medicine, vol. 4, no. 1, pp. 53-66, 2011.

[80] P. F. Mannaioni, A. Vannacci, and E. Masini, "Carbon monoxide: the bad and the good side of the coin, from neuronal death to anti-inflammatory activity," Inflammation Research, vol. 55, no. 7, pp. 261-273, 2006.

[81] J. T. Chapman, L. E. Otterbein, J. A. Elias, and A. M. K. Choi, "Carbon monoxide attenuates aeroallergen-induced inflammation in mice," American Journal of Physiology: Lung Cellular and Molecular Physiology, vol. 281, no. 1, pp. L209-L216, 2001.

[82] B. T. Ameredes, L. E. Otterbein, L. K. Kohut, A. L. Gligonic, W. J. Calhoun, and A. M. K. Choi, "Low-dose carbon monoxide reduces airway hyperresponsiveness in mice," American Journal of Physiology: Lung Cellular and Molecular Physiology, vol. 285, no. 6, pp. L1270-L1276, 2003.

[83] I. Horváth, L. E. Donnelly, A. Kiss, P. Paredi, S. A. Kharitonov, and P. J. Barnes, "Raised levels of exhaled carbon monoxide are associated with an increased expression of heme oxygenase-1 in airway macrophages in asthma: a new marker of oxidative stress," Thorax, vol. 53, no. 8, pp. 668-672, 1998.

[84] E. Bathoorn, D.-J. Slebos, D. S. Postma et al., "Antiinflammatory effects of inhaled carbon monoxide in patients with COPD: a pilot study," European Respiratory Journal, vol. 30, no. 6, pp. 1131-1137, 2007.

[85] T. Dolinay, A. M. K. Choi, and S. W. Ryter, "Heme oxygenase$1 / \mathrm{CO}$ as protective mediators in cigarette smoke- induced lung cell injury and chronic obstructive pulmonary disease," Current Pharmaceutical Biotechnology, vol. 13, no. 6, pp. 769-776, 2012.

[86] R. Foresti, M. G. Bani-Hani, and R. Motterlini, "Use of carbon monoxide as a therapeutic agent: promises and challenges," Intensive Care Medicine, vol. 34, no. 4, pp. 649-658, 2008. 
[87] K. W. Van Meter, J. Tintinalli, G. D. Kelen, and J. S. Stapczynski, "Carbon monoxide poisoning," in Emergency Medicine, pp. 1238-1242, McGraw Hill, New York, NY, USA, 2003.

[88] E. N. Allred, E. R. Bleecker, B. R. Chaitman et al., "Shortterm effects of carbon monoxide exposure on the exercise performance of subjects with coronary artery disease," The New England Journal of Medicine, vol. 321, no. 21, pp. 1426-1432, 1989.

[89] S. Faller, M. Foeckler, K. M. Strosing et al., "Kinetic effects of carbon monoxide inhalation on tissue protection in ventilatorinduced lung injury," Laboratory Investigation, vol. 92, no. 7, pp. 999-1012, 2012.

[90] A. Nakao, G. Faleo, M. A. Nalesnik, J. Seda-Neto, J. Kohmoto, and N. Murase, "Low-dose carbon monoxide inhibits progressive chronic allograft nephropathy and restores renal allograft function," American Journal of Physiology: Renal Physiology, vol. 297, no. 1, pp. F19-F26, 2009. 


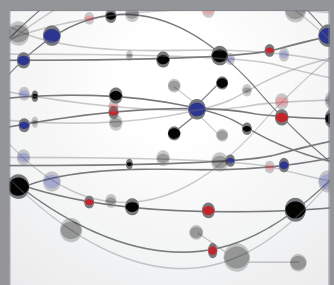

The Scientific World Journal
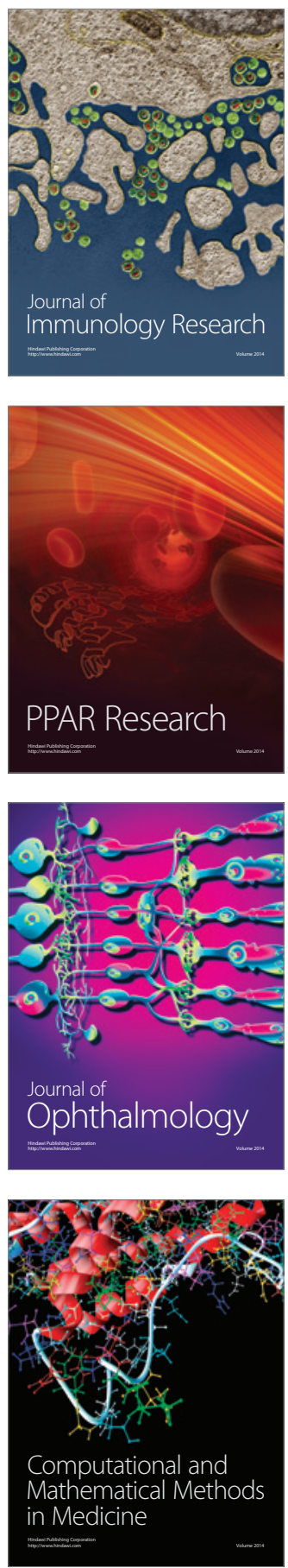

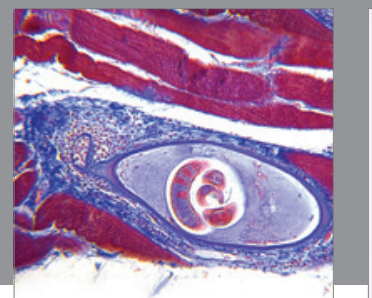

Gastroenterology

Research and Practice
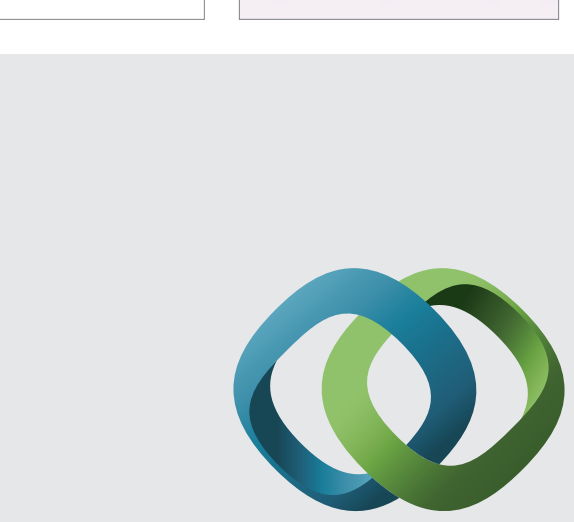

\section{Hindawi}

Submit your manuscripts at

http://www.hindawi.com
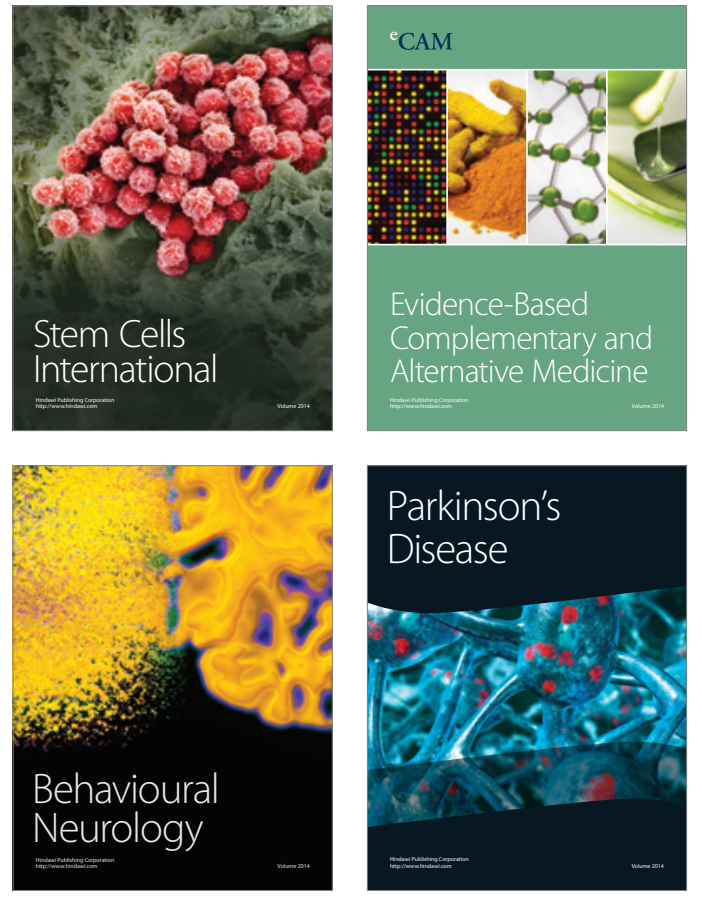
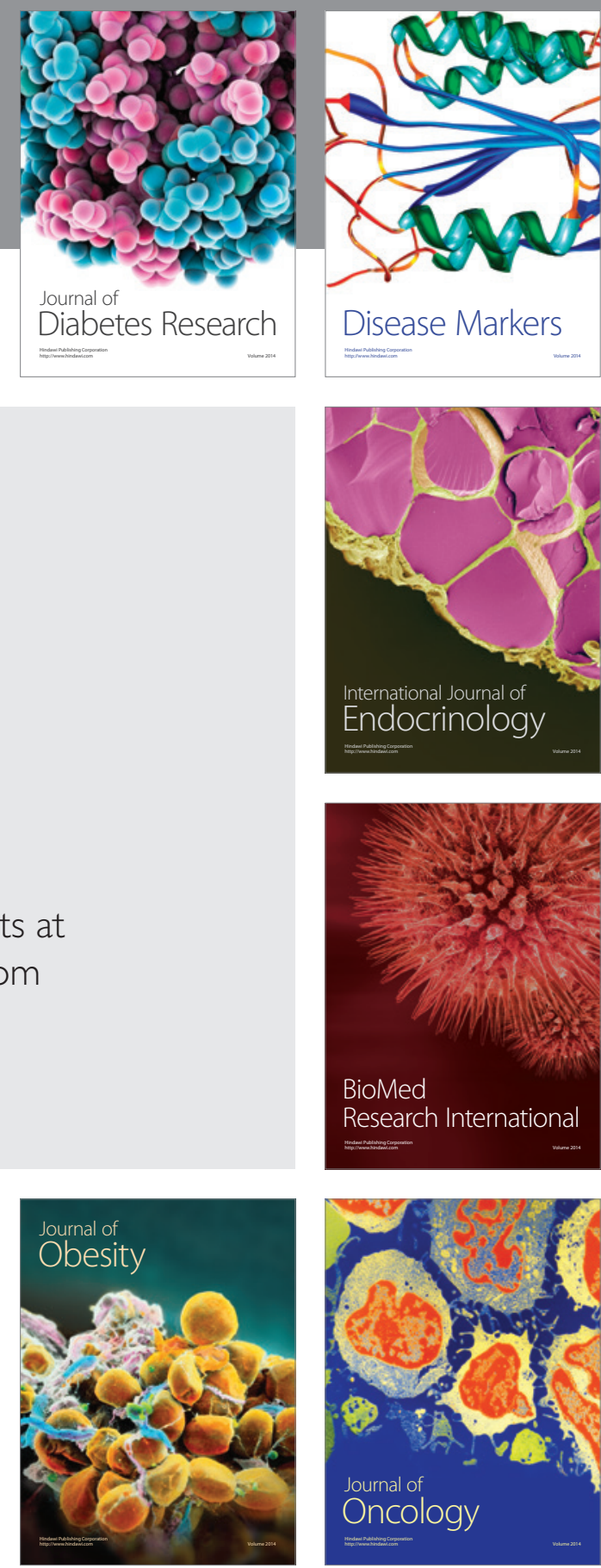

Disease Markers
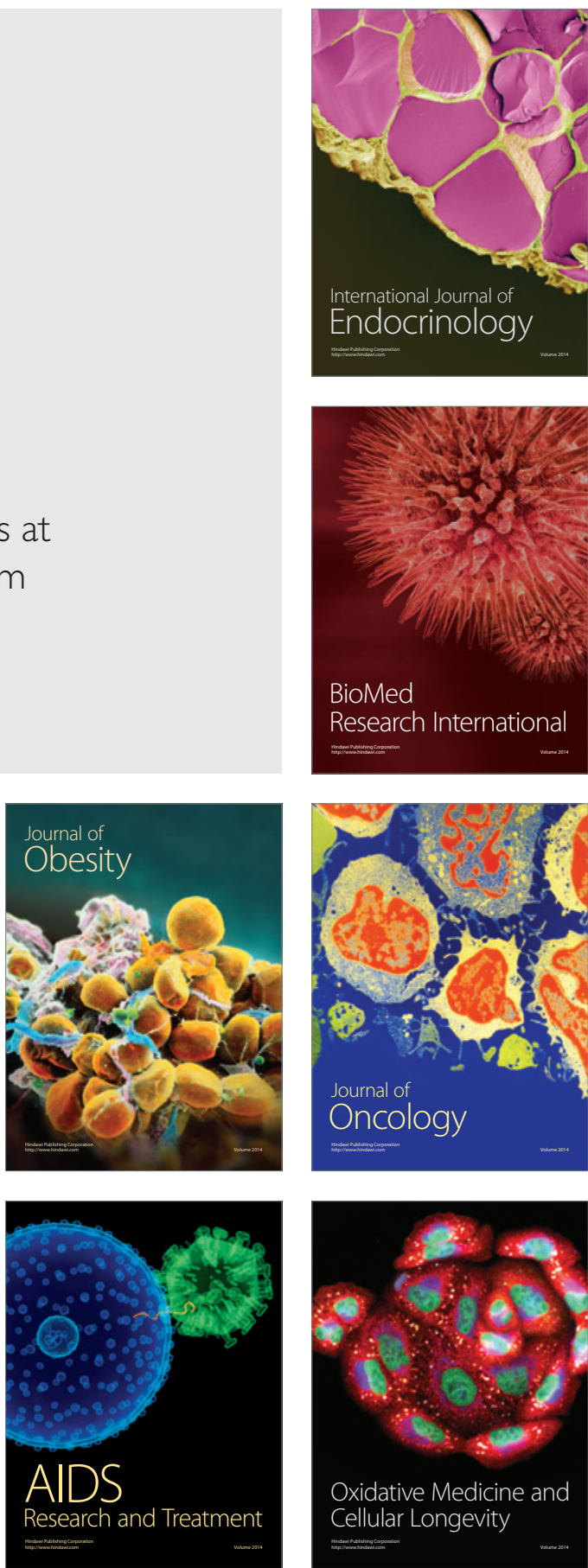